\title{
Identification of TRA-1-60-positive cells as a potent refractory population in follicular lymphomas
}

\author{
Katsuyoshi Takata $^{1,2}$ (D) | Ken Saito ${ }^{3}$ | Satoshi Maruyama ${ }^{4}$ | Tomoko Miyata-Takata $^{1}$ | \\ Hidekazu lioka $^{3}$ | Shujiro Okuda ${ }^{5}$ | Yiwei Ling ${ }^{5}$ | Kennosuke Karube ${ }^{6}$ | Yukari Miki ${ }^{7}$ | \\ Yoshinobu Maeda $^{8}$ | Tadashi Yoshino ${ }^{1}$ | Christian Steidl ${ }^{2,9}$ | Eisaku Kondo ${ }^{3}$ \\ ${ }^{1}$ Department of Pathology, Okayama University Graduate School of Medicine, Dentistry and Pharmaceutical Sciences, Okayama, Japan \\ ${ }^{2}$ Department of Lymphoid Cancer Research, Centre for Lymphoid Cancer, British Columbia Cancer, Vancouver, Canada \\ ${ }^{3}$ Division of Molecular and Cellular Pathology, Niigata University Graduate School of Medical and Dental Sciences, Niigata, Japan \\ ${ }^{4}$ Oral Pathology Section, Department of Surgical Pathology, Niigata University Hospital, Niigata, Japan \\ ${ }^{5}$ Bioinformatics Laboratory, Niigata University Graduate School of Medical and Dental Sciences, Niigata, Japan \\ ${ }^{6}$ Departments of Pathology and Cell Biology, Graduate School of Medicine, University of the Ryukyus, Nishihara, Japan \\ ${ }^{7}$ Department of Medical Hygiene, Medical Technology Course, Kochi Gakuen Junior College, Kochi, Japan \\ ${ }^{8}$ Department of Hematology and Oncology, Okayama University Hospital, Okayama, Japan \\ ${ }^{9}$ Department of Pathology and Laboratory Medicine, University of British Columbia, Vancouver, Canada
}

\section{Correspondence}

Katsuyoshi Takata, Department of Lymphoid

Cancer Research, Centre for Lymphoid

Cancer, British Columbia Cancer, Vancouver,

Canada.

Email: katsuyoshi.t@h5.dion.ne.jp

Eisaku Kondo, Division of Molecular and

Cellular Pathology, Niigata University

Graduate School of Medical and Dental

Sciences, Niigata, Japan.

Email: ekondo@med.niigata-u.ac.jp

Funding information

Japan Society for the Promotion of Science,

Grant/Award Number: 16 K15245 and

24790350
Despite receiving rituximab-combined chemotherapy, follicular lymphoma (FL) patients often suffer tumor recurrence and understand that the cause of relapse in FL would thus significantly ameliorate the tumor therapeutics. In the present study, we show that TRA-1-60-expressing cells are a unique population in FL, converge to the conventional stem cell marker Oct3/4 and ALDH1-positive population, and resist current B-lymphoma agents. TRA-1-60 expression was observed in scattered lymphoma cells in FL tissues only as well as in resting B-lymphocytes inside germinal centers. Retrospective comparison between recurrent and cognate primary tissues showed that the number of TRA-1-60-positive cells from rituximab, cyclophosphamide, hydroxydaunorubicin, vincristine, and prednisone (R-CHOP)-treated FL had increased relative to primary tissue, a finding corroborated by assays on different rituximab-treated FL cell lines, FL-18 and DOHH2, wherein TRA-positive cell numbers increased over 10 -fold compared to the untreated sample. Concordantly, scanty TRA-1-60-positive FL-18 cells implanted s.c. into mice evinced potent tumor-initiating capacity in vivo, where tumors were 12 -fold larger in volume $(P=0.0021<0.005)$ and 13 -fold heavier in weight $(P=0.0015<0.005)$ compared to those xenografted from TRA-negative cells. To explain these results, gene expression profiling and qPCR analysis indicated that TRA-1-60-positive cells defined a distinct population from that of TRA-negative cells, with upregulation of multiple drug transporters and therapeutic resistance genes. Hence, TRA-1-60-expressing cells in FL are considered

This is an open access article under the terms of the Creative Commons Attribution-NonCommercial License, which permits use, distribution and reproduction in any medium, provided the original work is properly cited and is not used for commercial purposes.

(c) 2018 The Authors. Cancer Science published by John Wiley \& Sons Australia, Ltd on behalf of Japanese Cancer Association. 
to be vigorously intractable against conventional therapeutic agents, which may explain its refractory recurrence.

KEYWORDS

drug resistance, follicular lymphoma, rituximab, TRA-1-60, tumor recurrence

\section{1 | INTRODUCTION}

Follicular lymphoma (FL) is the second most common subtype of non-Hodgkin lymphoma, accounting for approximately $20 \%$ of all lymphomas. ${ }^{1}$ With the advent of rituximab, overall survival and progression-free survival rates have improved; however, about half of FL patients experience relapse within 5 years, representing a considerable setback. $^{2}$

Definitive explanation for relapse is not fully disclosed, although several unresolved theories have been offered, pertaining to genomic or clonal evolution, microenvironment and other elements. ${ }^{3-6}$ Concretely, these recent studies reported several specific gene mutations including TNFRSF14, CREBBP, EP300, KLHL6 and so on that were supposed to be critical for immune evasion, biological transformation and progression of $\mathrm{FL}^{3-6}$ which provided the basis of lymphoma-initiating cells from the point of genomic DNA mutations. For advanced tumor therapeutics in carcinomas, glial malignancies and leukemias, so-called cancer initiating cells or cancer stem cells, have presently been recognized as key factors in relapse and therapeutic resistance. ${ }^{7-9}$ Cancer stem cells (CSC) in solid tumors have been vigorously studied; however, CSC, analogously lymphoma stem cells in lymphoma, were mainly introduced for limited subtypes of lymphoma such as chronic lymphocytic leukemia/small lymphocytic lymphoma (CLL/SLL) and Hodgkin lymphoma, and more information should be collected about other types of lymphomas, especially intractable lymphomas including FL. ${ }^{10,11}$

To identify cancer stem cells, previous reports used several markers (eg, OCT4, SOX2, KLF4, Nanog, SSEA-4, and ALDH1), among which the former three were genes to induce mouse or human somatic cells to become pluripotent stem cells. ${ }^{12,13}$ These markers needed to be used in combination, but, recently, several groups discovered a new marker TRA-1-60 which imparted stronger stem cell properties than other markers. ${ }^{14,15}$ TRA-1-60 is a neuraminidase-resistant carbohydrate epitope expressed on podocalyxin-like 1 , belonging to the CD34-related family of sialomucin, and it is expressed on the surface of human embryonic stem cells (ESC) and induced pluripotent stem cells (iPS cells), which becomes downregulated as cell-differentiated. ${ }^{16}$

In the present study, we aimed to find a clue for the intractability of FLs which causes relapse and drug resistance, leading to fatal outcomes despite the current advanced therapeutics using antibody drug. Therefore, we first histologically examined TRA-1-60 expression on $\mathrm{FL}$ tissues and germinal centers as its origin in order to examine correlation with expression of cellular markers including conventional stem cell markers such as Oct3/4 and ALDH1, which provide biological insight on cellular properties, as TRA-1-60 is one of the critical cellular markers of stem cells. We observed a rare population of follicular lymphoma cells specifically expressing TRA-1-60 as well as germinal center B cells. Remarkably, we found that the number of TRA-1-60-positive cells increased in the recurrent samples that resisted therapy, and they showed prominent drug resistance and tumor-forming capacity, properties not observed in the TRA-1-60-negative FL population by in vitro assays using two different human FL cell lines. Our results indicate that TRA-1-60, which might provide follicular lymphoma cells with resistant properties against lymphoma therapeutics, is expressed in a small population of FL cells, and this specific population could be highly significant to explain the recalcitrance of FL.

\section{2 | MATERIALS AND METHODS}

\section{1 | Patient samples}

Formalin-fixed paraffin embedded tissue (FFPET) of 30 untreated FL grade 1 patients and 17 paired (untreated and recurrent after rituximab, cyclophosphamide, hydroxydaunorubicin, vincristine, and prednisone [R-CHOP] therapy) FL patients, and fresh frozen samples of five untreated FL patients were used (Tables 1 and 2). This study was conducted with the approval of the Institutional Review Board of Okayama University, Okayama, Japan. All study procedures were conducted in accordance with the guidelines of the Declaration of Helsinki.

\section{2 | Immunohistochemistry, immunofluorescence, and measurement of TRA-1-60- expressing lymphoma cells in patient samples}

For conventional immunohistochemistry and fluorescent immunostaining of paraffin-embedded tumor tissues, primary and secondary antibodies were used as listed in Table 3. Number of TRA1-60-positive cells in reactive tissues and FL tissues was counted at a total of nine high-power fields (HPF) ( $\times 400$ field) of randomly chosen perivascular areas in the same specimen.

\section{3 | Laser capture microdissection, long- distance PCR for $t(14 ; 18)$ and DNA sequencing of PCR products}

Laser capture microdissection was carried out for freshly frozen sections using the Leica LMD 7000 laser microdissection system (Leica Microsystems, Wetzlar, Germany) as previously described. ${ }^{17}$ Briefly, 15 to 20 TRA-1-60-positive or TRA-1-60-negative cells were 
TAB LE 1 Clinicopathological characteristics of 30 primary FL patients

\begin{tabular}{|c|c|c|c|c|c|c|}
\hline Patient no. & Age (y) & Gender & Clinical stage & Histological grade & $\begin{array}{l}\text { No. of TRA-1-60+ } \\
\text { cells (/3 HPF) }\end{array}$ & $\begin{array}{l}\text { Primary site } \\
\text { (nodal/extranodal) }\end{array}$ \\
\hline 1 & 62 & $M$ & Unknown & 1 & 10 & Nodal \\
\hline 3 & 61 & $M$ & III & 1 & 17 & Nodal \\
\hline 4 & 69 & $\mathrm{~F}$ & III & 1 & 4 & Nodal \\
\hline 7 & 84 & $\mathrm{~F}$ & I & 1 & 31 & Primary lung \\
\hline 8 & 71 & $M$ & II & 1 & 15 & Nodal \\
\hline 9 & 67 & M & ॥ & 1 & 20 & Nodal \\
\hline 10 & 81 & $M$ & Unknown & 1 & 6 & Nodal \\
\hline 14 & 51 & $\mathrm{~F}$ & Unknown & 1 & 9 & Nodal \\
\hline 15 & 50 & $\mathrm{~F}$ & II & 1 & 11 & Nodal \\
\hline 16 & 56 & $M$ & Unknown & 1 & 4 & Nodal \\
\hline 17 & 71 & M & III & 1 & 3 & Nodal \\
\hline 18 & 60 & $\mathrm{~F}$ & II & 1 & 3 & Nodal \\
\hline 19 & 59 & $\mathrm{~F}$ & IV & 1 & 5 & Nodal \\
\hline 20 & 62 & $M$ & III & 1 & 10 & Nodal \\
\hline 21 & 82 & $\mathrm{~F}$ & III & 1 & 6 & Nodal \\
\hline 28 & 65 & $\mathrm{~F}$ & 1 & 1 & 7 & Primary intestinal \\
\hline 29 & 58 & M & 1 & 1 & 4 & Primary intestinal \\
\hline 30 & 49 & $\mathrm{~F}$ & I & 1 & 4 & Primary intestinal \\
\hline
\end{tabular}

FL, follicular lymphoma; HPF, high-power fields.

collected and total DNA was isolated by Qiagen tissue microkit (QIAGEN, Hilden, Germany). Long-distance PCR was carried out as described in a previous report. ${ }^{18}$ When we did not obtain any amplification, re-amplification was done using $0.5 \mu \mathrm{L}$ of first-round PCR product. Primer sets are shown in Table 4. Primers for sequencing the PCR products to confirm $b c /$-2-IgH gene fusion are listed in Table 4 as reported previously. ${ }^{18}$ Sequences of $\mathrm{lgH}$ and $b \mathrm{cl}-2$ gene loci were searched by UCSC genome browser (https://genome.ucsc.edu/).

\subsection{Cell lines and drug treatment assay}

Two human follicular lymphoma cell lines both bearing $t(14 ; 18)$ (q32, q21), FL-18 and DOHH2 were used in the present study. Both FL-18 and DOHH2 cells were cultured in RPMI 1640 media (Life
Technologies Corporation, Waltham, MA, USA) supplemented with $10 \%$ FBS, respectively. These cells were treated with rituximab $(10 \mu \mathrm{g} / \mathrm{mL})$. As rituximab-induced cell death was reported to be attributed to cross-linking by immunoglobulin $F\left(a^{\prime}\right)$ and complementdependent cytotoxicity, goat antihuman IgG cross-linker ( $F c \gamma$ specific, 109-005-078; Jackson ImmunoResearch Inc., West Grove, PA, USA) was used as previously described. ${ }^{19}$ Number of TRA-160-positive or TRA-1-60-negative, and Annexin V-FITC cells were counted by FACS analysis 12 and 24 hours after the drug treatment.

\subsection{Cell sorting and lymphoma xenografts}

Rituximab-treated FL-18 cells were fractionated by FACS Aria. Cells $\left(2 \times 10^{3}\right)$ at $70 \%$ purity for TRA-1-60-positive cells or the same 
TAB LE 2 Clinicopathological characteristics of 17 recurrent FL patients

\begin{tabular}{|c|c|c|c|c|c|c|c|c|}
\hline Patient no. & Age $(y)$ & Gender & CD10 & BCL2 & Clinical stage & Histological grade & Therapy & $\begin{array}{l}\text { Time of } \\
\text { recurrence } \\
\text { (months) }\end{array}$ \\
\hline 2 & 59 & $\mathrm{~F}$ & + & + & II & 1 & $\mathrm{R}-\mathrm{CHOP}$ & 52 \\
\hline 3 & 77 & $\mathrm{~F}$ & - & + & IV & 1 & R-monotherapy & 78 \\
\hline 6 & 54 & $\mathrm{~F}$ & + & + & IV & 1 & $\mathrm{R}-\mathrm{CHOP}$ & 24 \\
\hline 7 & 41 & $\mathrm{~F}$ & + & + & III & 1 & $\mathrm{R}-\mathrm{CHOP}$ & 156 \\
\hline 8 & 58 & $M$ & + & + & III & 1 & $\mathrm{R}-\mathrm{CHOP}$ & 85 \\
\hline 9 & 68 & $\mathrm{~F}$ & + & + & IV & 1 & $\mathrm{R}-\mathrm{CHOP}$ & 36 \\
\hline 12 & 58 & M & + & + & III & 1 & $\mathrm{R}-\mathrm{CHOP}$ & 85 \\
\hline 13 & 59 & M & + & - & IV & 1 & $\mathrm{R}-\mathrm{CHOP}$ & 7 \\
\hline 14 & 85 & $\mathrm{~F}$ & + & + & 1 & 1 & R-THP-COP & 33 \\
\hline 15 & 67 & $\mathrm{~F}$ & + & + & III & 1 & $\mathrm{R}-\mathrm{CHOP}$ & 15 \\
\hline 16 & 71 & $M$ & + & + & 1 & 1 & $R+R T$ & 48 \\
\hline 17 & 73 & $M$ & + & + & IV & 1 & $\mathrm{R}-\mathrm{CHOP}$ & 24 \\
\hline
\end{tabular}

CHOP, cyclophosphamide, hydroxydaunorubicin, vincristine, and prednisone; FL, follicular lymphoma; R, rituximab; RT, radiation therapy.

number of TRA-negative cells at $99 \%$ purity were injected s.c. into the bilateral sites of the posterior flank of three NOD/SCID mice, respectively. Tumor volume was calculated as length $\times(\text { width })^{2} \times 1 / 2$, as this formula was applied to measuring volume in the previous studies. $^{20}$

\section{6 | Quantitative real-time PCR for gene profiling}

To profile gene expressions of the TRA-1-60-positive cell population with those of the TRA-negative population in two different FL lines, FL-18 and DOHH2 cells, quantitative real-time PCR using CDNAs derived from each population in these lines was carried out for a total of 168 indicated drug resistance-related genes.

Detailed methods of each of the above sections are described in "Document S1".

\section{RESULTS}

\section{1 | Expression of TRA-1-60 on germinal center B cells and its relationship with conventional stem cell markers}

Endogenous expression of TRA-1-60 which is recognized as one of the critical stem cell markers, was detected on germinal center cells within reactive lymph nodes. Generally, stem cell marker-positive tumor cells show drug resistance, ${ }^{21}$ and this was examined for its relationship to other conventional stem cell markers (Oct3/4 and
ALDH1A1) by double immunofluorescence to gain an insight into cellular properties. All markers (Oct3/4, ALDH1A1, and TRA-1-60) were partially expressed on the germinal center cells (Figure 1A). Oct3/4 was positive for a portion of centroblasts and centrocytes, and ALDH1A1 was positive for a portion of centroblasts and follicular dendritic cells. TRA-1-60 was also expressed for a portion of centroblasts and centrocytes, and double immunofluorescence using CD20 or CD3 in combination with anti-TRA-1-60 antibody showed that most TRA-1-60-expressing cells were CD20 positive, indicating they were germinal center $B$ cells (Figure 1B,C). In double immunofluorescence using anti-ALDH1A1 and CD21, ALDH1A1 was expressed on a comparable number of follicular dendritic cells (FDC) inside the germinal center (Figure 1D and Figure S1A). TRA1-60 expression was mainly independent of ALDH1A1 expression inside the germinal center (Figure 1E). Moreover, the TRA-1-60expressing germinal center $\mathrm{B}$ cells were negative for $\mathrm{Ki}-67$, suggesting they were quiescent in the cell cycle (Figure 1F).

\section{2 | Distribution of TRA-1-60-positive cells in FL tissues}

Insofar as the neoplastic counterpart to the normal lymphoid follicle, $\mathrm{FL}$, arises from the germinal center of lymphoid tissues, we next investigated the distribution of TRA-1-60-positive cells in 30 tissue samples from FL patients because it is important to provide histological information on the distribution of TRA-1-60-positive cells. Patient information of these cases is provided in Table 1. Scattered 
TABLE 3 Summary of primary and secondary antibodies

\begin{tabular}{|c|c|c|c|}
\hline Antibody & Source & Type & Dilution \\
\hline TRA-1-60 & $\begin{array}{l}\text { Merck Millipore, Darmstadt, } \\
\text { Germany }\end{array}$ & MAB4360 mouse IgM & $1: 100$ \\
\hline Oct3/4 & $\begin{array}{l}\text { Cell Signaling Technology, Inc., } \\
\text { Danvers, MA }\end{array}$ & PAb (rabbit) & $1: 100$ \\
\hline CD20 & Nichirei, Japan & L26 mouse mAb & $1: 100$ \\
\hline CD3 & $\begin{array}{l}\text { Novocastra, Newcastle Upon } \\
\text { Tyne, UK }\end{array}$ & LN10 mouse mAb & $1: 200$ \\
\hline CD10 & $\begin{array}{l}\text { Novocastra, Newcastle Upon } \\
\text { Tyne, UK }\end{array}$ & $56 \mathrm{C} 6$ mouse $\mathrm{mAb}$ & $1: 100$ \\
\hline CD21 & Abcam, Cambridge, UK & EP3093 rabbit mAb & $1: 200$ \\
\hline $\mathrm{Ki}-67$ & $\begin{array}{l}\text { Novocastra, Newcastle Upon } \\
\text { Tyne, UK }\end{array}$ & MIB-1 PAb (rabbit) & $1: 2500$ \\
\hline $\mathrm{BCL} 2$ & $\begin{array}{l}\text { Epitomics, Inc., Burlingame, } \\
\text { CA }\end{array}$ & E17 rabbit $\mathrm{mAb}$ & $1: 100$ \\
\hline ALDH1A1 & Abcam, Cambridge, UK & Rabbit mAb & $1: 100$ \\
\hline Factor VIII (VWF) & Dako, Glostrup, Denmark & PAb (rabbit) & $1: 200$ \\
\hline IgM (isotype control) & Sigma Aldrich, St Louis, MO & MOPC 104E & $1: 100$ \\
\hline $\begin{array}{l}\text { Anti-mouse IgM } \\
\text { peroxidase conj. }\end{array}$ & $\begin{array}{l}\text { Jackson ImmunoResearch Inc., } \\
\text { West Grove, PA }\end{array}$ & Secondary Ab & $1: 500$ \\
\hline $\begin{array}{l}\text { Anti-mouse lgM } \\
\text { Cy3-conj. }\end{array}$ & $\begin{array}{l}\text { Jackson ImmunoResearch Inc., } \\
\text { West Grove, PA }\end{array}$ & Secondary Ab & $1: 500$ \\
\hline $\begin{array}{l}\text { Anti-mouse IgG Alexa } \\
\text { Fluor } 488\end{array}$ & $\begin{array}{l}\text { Life Technologies Corp., } \\
\text { Waltham, MA }\end{array}$ & Secondary Ab & $1: 400$ \\
\hline $\begin{array}{l}\text { Anti-rabbit lgG Alexa } \\
\text { Fluor } 488\end{array}$ & $\begin{array}{l}\text { Life Technologies Corp., } \\
\text { Waltham, MA }\end{array}$ & Secondary Ab & $1: 400$ \\
\hline $\begin{array}{l}\text { Anti-mouse IgG Alexa } \\
\text { Fluor } 555\end{array}$ & $\begin{array}{l}\text { Life Technologies Corp., } \\
\text { Waltham, MA }\end{array}$ & Secondary Ab & $1: 400$ \\
\hline $\begin{array}{l}\text { Alexa Fluor } 350 \\
\text { streptavidin conj. }\end{array}$ & $\begin{array}{l}\text { Life Technologies Corp., } \\
\text { Waltham, MA }\end{array}$ & Secondary Ab & $1: 500$ \\
\hline
\end{tabular}

TABLE 4 Primer sequences used in the present study

\begin{tabular}{|c|c|c|}
\hline Primer & Sequence $(\mathrm{Fw})$ & Sequence (Rv) \\
\hline A2 & TTATGGTTATGTGTCTTTCTGGGGGATGG & TTGTCCAGGTGTTTTGCTCAGTAG \\
\hline A4 & TGTTGGTGACATTTGATGGCTTTGCTGAGAGGTA & TTGTCCAGGTGTTTTGCTCAGTAG \\
\hline B1 & GTCTCAATGGGTTTTGCTCCTTCA & TTGTCCAGGTGTTTTGCTCAGTAG \\
\hline B3 & TTGCTAATGACATCCTCTAAGTCCTCCTCT & TTGTCCAGGTGTTTTGCTCAGTAG \\
\hline B4 & TGAAAGAAACGAAAGCAACAGGAACA & TTGTCCAGGTGTTTTGCTCAGTAG \\
\hline B5 & CAGAGAGCCAGAAGCGTCAGGTC & TTGTCCAGGTGTTTTGCTCAGTAG \\
\hline Case 1 nested & AGGAGACCCAGCACCCTTAT & CAAGCCATGTGAACATTCTGA \\
\hline
\end{tabular}

TRA-1-60-expressing CD20-positive B cells were mainly detected at the marginal area of neoplastic follicles of $\mathrm{FL}$, close to small blood vessels indicated as "HEV" (Figure 2A,B). Double immunofluorescence using TRA-1-60 and Factor VIII (von Willebrand factor) corroborated their distribution at perivascular areas (Figure 2B, right image) and they were rarely found at the center of neoplastic follicles. They were also confirmed by coincident expression of both CD10 and BCL2 by triple immunofluorescence as indicated by dotted circles (Figure 2C, 
(A)

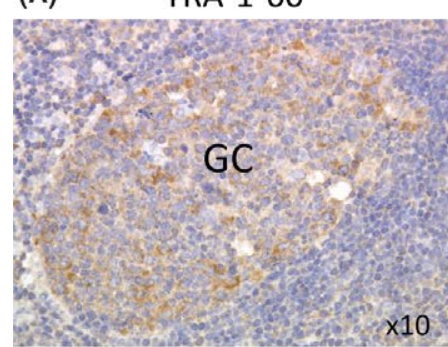

(B)

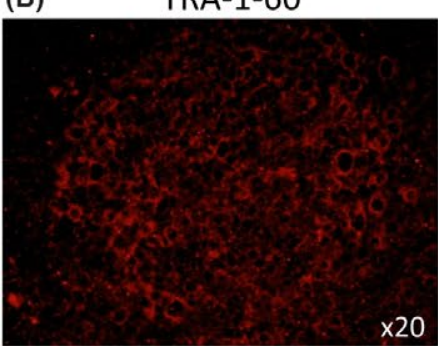

(C)

TRA-1-60

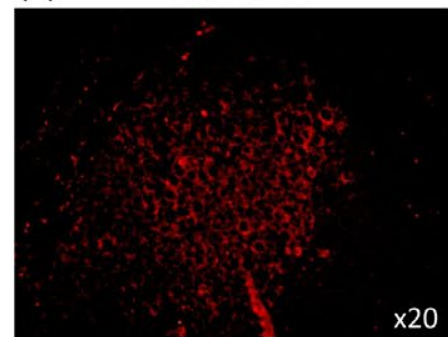

$\times 20$

CD21
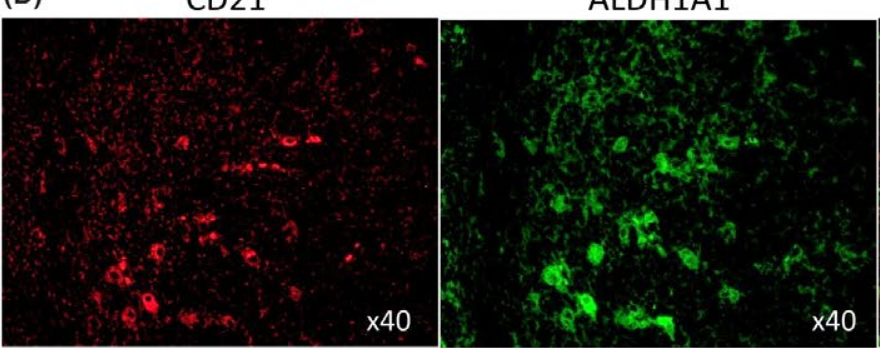

$\times 20$
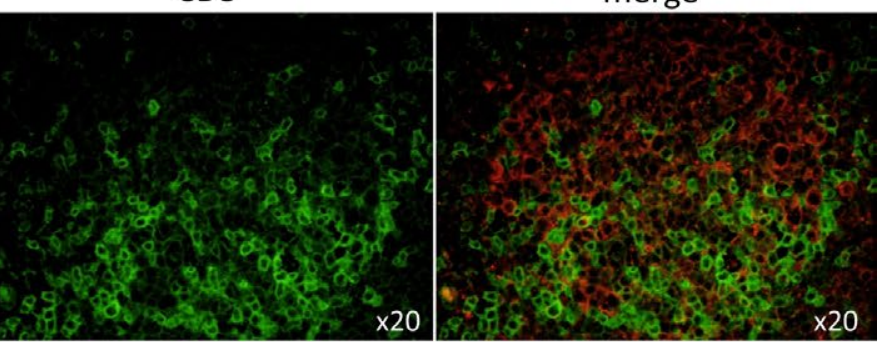

merge
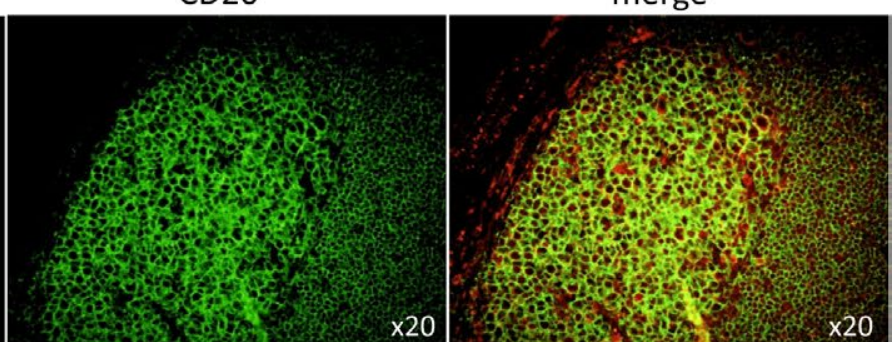

$\times 20$

(E)

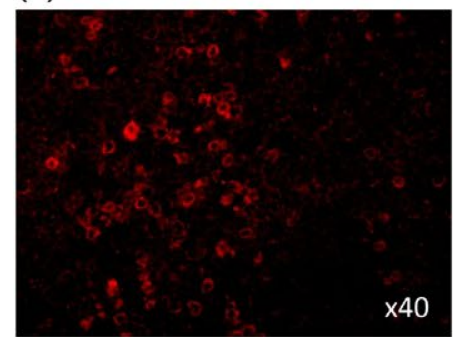

(F) TRA-1-60

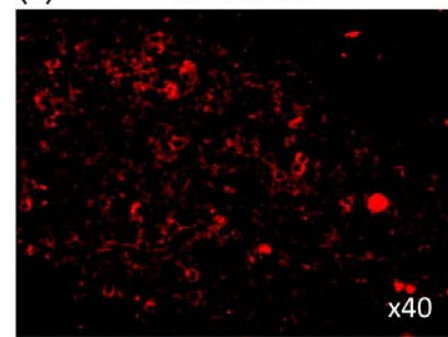

ALDH1A1

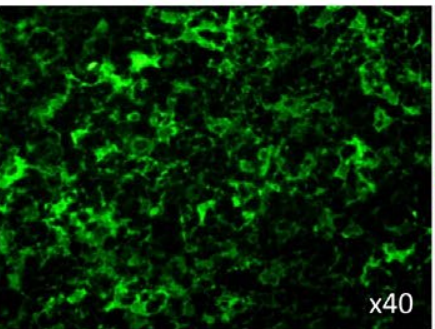

Ki-67

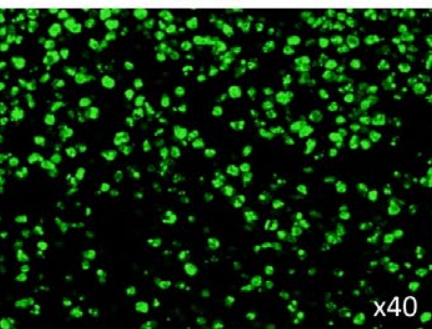

merge

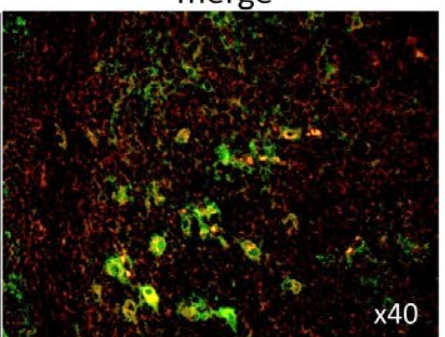

merge

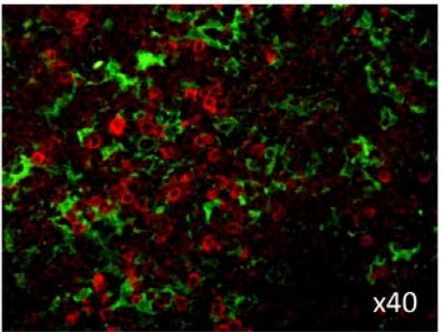

merge

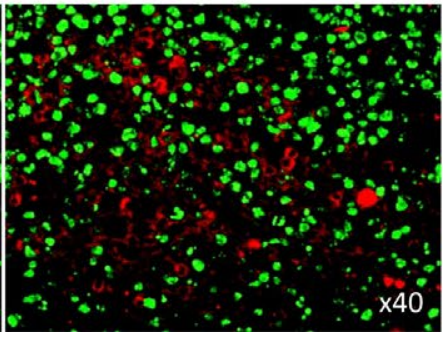


FIG URE 1 Expression of TRA-1-60, and conventional stem cell markers (Oct3/4, ALDH1) in the germinal center and double immunostaining. A, All markers were expressed in a part of the germinal center cells. Oct3/4 was positive for a part of the centroblasts and centrocytes, ALDH1 was positive for a part of the centroblasts and follicular dendritic cells, and TRA-1-60 was positive for a part of the centroblasts and centrocytes ( $\times 10)$. B,C, Most of the TRA-1-60 was coexpressed with CD20 rather than with CD3 ( $\times 20$, respectively). D, Comparable number of CD21-positive cells (follicular dendritic cells [FDC]) expressed ALDH1 inside the germinal center ( $\times 40)$.

E, Double immunofluorescence of TRA-1-60 and ALDH1 showed that most TRA-1-60 was not coexpressed with ALDH1 ( $\times 40$ ). F, Double immunofluorescence of TRA-1-60 and Ki-67 showed TRA-1-60-positive cells negative for Ki-67, suggesting that they were in the resting stage in the cell cycle $(\times 40)$. GC, germinal center

upper and lower panels). TRA-1-60-positive cells were independent of CD21-positive FDC in FL tissues (Figure S1B). Moreover, they were negative for $\mathrm{Ki}-67$ whereas some ALDH1A1-expressing cells were positive for Ki-67 (Figure 2D,E), suggesting that these TRA-positive cells were in cell cycle arrest. For confirmation of specificity of all histological staining using anti-TRA-1-60 antibody, tissue staining with mouse IgM as a control was carried out (Figure S1C).

\section{3 | TRA-1-60-expressing cells are neoplastic in FL tissues}

Based on the immunofluorescence results, we further examined whether TRA-1-60-positive cells in FL tissues were neoplastic. Accordingly, single cell microdissection was used to isolate TRA-160-positive cells from patient specimens (Figure 3A, left panel, indicated by dotted circles). After extraction of genomic DNA from five to 10 isolated cells on the same specimen, long-distance PCR was first carried out, then sequentially semi-nested PCR was done using the first amplicon to demonstrate the specific gene fusion, $t(14 ; 18 / I G H-B C L 2)$ (Table 4). As a control, DNA samples were collected from TRA-negative cells and also from CD3-positive cells by the same procedure, respectively. Consequently, semi-nested PCR products in combination with long-PCR showed co-migration by electrophoresis between the DNA from the TRA-positive cells and the negative cells in all three patient cases, which indicated specific chromosomal translocation in $\mathrm{FL}, \mathrm{t}(14 ; 18)$, but not in the samples from CD3-positive cells (Figure 3A, right panel). Further sequence analysis of the amplicons evinced $b c /-2-l g H$ gene fusion as that of patient numbers 1 through 3 (corresponding to case 1 to case 3 ) demonstrating TRA-positive cells as neoplastic with the junction of the fusion identical between TRA-positive and TRA-negative samples (Figure 3B). In these three patients, IGH-BCL2 fusion was also confirmed by immuno-FISH study (patients 1-3) (Figure S2). ${ }^{18}$

\section{4 | Increase of TRA-1-60-positive lymphoma cells in recurrent $\mathrm{FL}$ tissues}

To address the relationship of TRA-1-60 with the intractability of recurrent FL, we first attempted to find a difference in TRA1-60 expression in tumor cells between the primary tissue and the relapsed tissue of FL within the same individual. Seventeen cases of paired primary and relapsed FL samples from the same patient were used for comparison of TRA-positive cell numbers. Clinicopathological information of these 17 cases with recurrence is shown in Table 2. All relapsed cases were from rituximabcombination therapy. In a representative case, in patient \#5, the number of TRA-1-60-positive cells in the recurrent tissue increased up to eight-fold compared to primary tissue, maintaining a similar adjacent vascular distribution (Figure $3 C$ ). Distribution of TRA-160-positive lymphoma cells was mostly similar to randomly chosen high-power fields ( $\times 40$ magnification) in the initial and recurrence tissue, respectively (patient \#10, Figure S3A). A summary of the 17 pairwise comparisons is shown in Figure 3D; average numbers of TRA-1-60-positive cells in the primary and recurrent samples in each case are shown as comparison bars. Although the number of TRA-1-60-positive cells varied to some extent in each case, the relapsed tissues invariably contained more TRA-expressing lymphoma cells, representing increases of between two- and eightfold relative to primary tissues. Such increases were statistically significant in all cases $(P<0.05)$.

\subsection{Population of TRA-1-60-positive cells was expanded by rituximab treatment in FL-derived cell lines}

Following the observation of increased TRA-1-60-positive cell numbers in relapsed FL samples, we further studied this distinctive phenomenon using two human FL cell lines, FL-18 and DOHH2, both carrying $t(14 ; 18)$ established from different FL patients. First, we examined the native response to rituximab in the two lines, and they showed growth retardation especially with treatment of cross-linked rituximab (rituximab + anti-lgG) in a time-dependent method (Figure 4A). We determined a rituximab concentration of $10 \mu \mathrm{g} / \mathrm{mL}$ in combination with $50 \mu \mathrm{g} / \mathrm{mL}$ of antihuman IgG (used for cross-linking rituximab to enhance the cytotoxic effect of rituximab in vitro). This dose yielded the $\mathrm{IC}_{50}$ for FL-18 cells and $25 \%$ of growth suppression for DOHH2 12 hours post-treatment. TRA-160 -expressing cells accounted for $0.05 \%-0.06 \%$ of the total population of $\mathrm{FL}-18$ and $0.05 \%-0.09 \%$ of $\mathrm{DOHH} 2$ in the native condition (Figure 4B). In FACS analysis, the percentage of TRA-1-60-positive cells did not change significantly in the single-rituximab-treated group from untreated cells; however, the percentage of the cells treated with cross-linked rituximab increased up to 10 -fold compared to untreated cells at 12 hours $(0.61 \%$ vs $0.06 \%)$, and it dramatically increased, up to 26 -fold (1.34\% vs $0.05 \%)$ at 24 hours in FL-18 cells $(P<0.001)$. In DOHH2 cells, TRA-positive cells increased up to four-fold at 12 hours and up to 19 -fold at 24 hours by treatment with cross-linked rituximab $(P<0.001)$ (Figure 4B,C). FACS analysis 
(A)

TRA-1-60

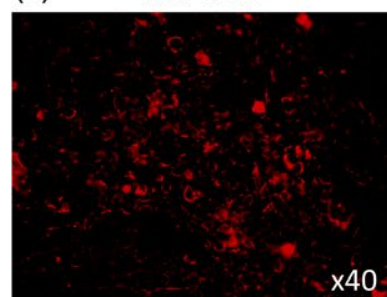

(B)

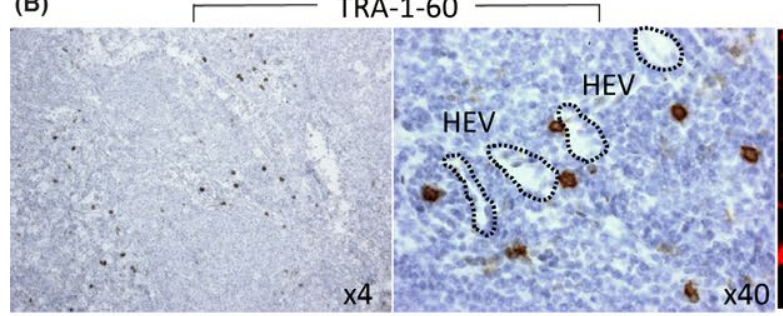

(C)

TRA-1-60

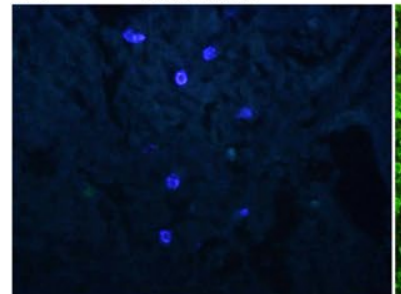

$\mathrm{BCL} 2+\mathrm{CD} 10$

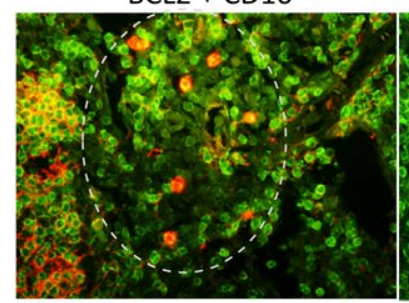

(D)

ALDH1A1

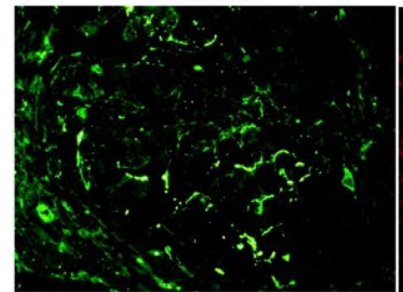

(E)

TRA-1-60

$\mathrm{BCL} 2$

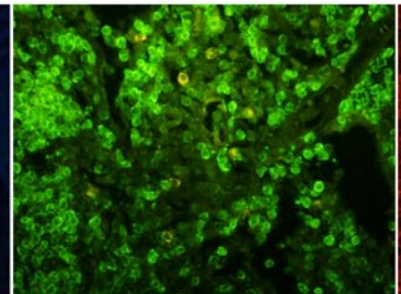

TRA-1-60 + BCL2

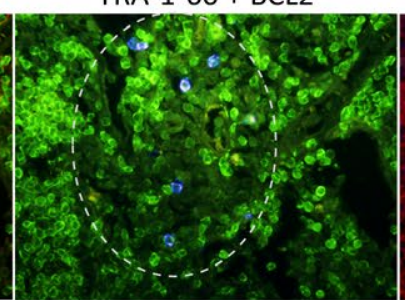

Ki-67

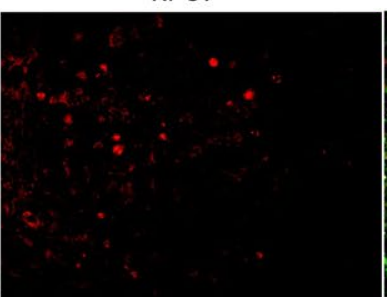

Ki-67

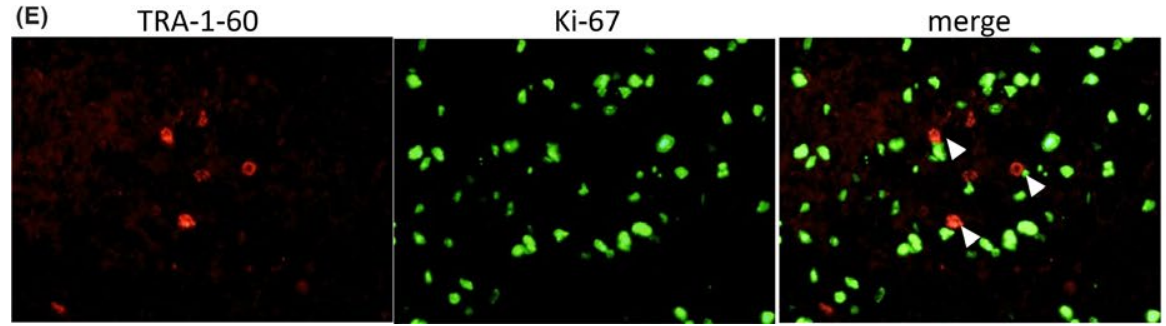

merge

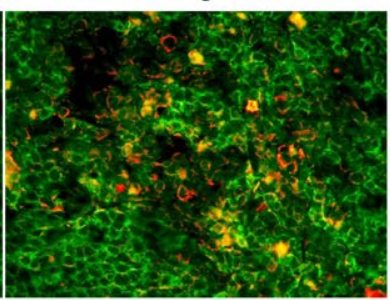

TRA-1-60 + Factor VIII

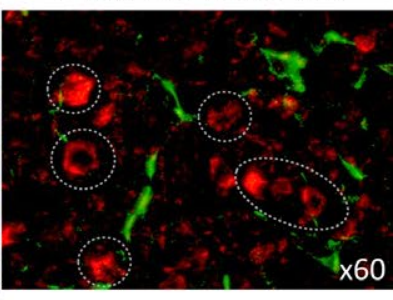

CD10

FIG URE 2 Representative TRA-1-60 expression in primary follicular lymphoma (FL) samples by an initial biopsy. A, TRA-1-60-expressing cells shared CD20 expression inside neoplastic follicle of FL (grade 1 ) ( $\times 40)$. B, TRA-1-60-positive cells were located at perivascular area by immunohistochemistry (left; $\times 4$, middle; $\times 40$ ). HEV, high endothelial venule. Double immunofluorescence with Factor VIII (green) and TRA1-60 (red) (right; $\times 60$ ). C, TRA-1-60-positive cells coexpressed with both CD10 and BCL2 by combination of double immunofluorescence. TRA-1-60 (Alexa 350; blue), Bcl-2 (Alexa 488), CD10 (Cy3). Bcl-2-CD10 double-positive, TRA-Bcl-2 double-positive, and TRA-CD10 doublepositive cells are indicated by dotted circles in each image ( $\times 40)$. D, ALDH1A1-positive cells were follicular dendritic cells as seen in the non-neoplastic germinal center, and some cells coexpressed with $\mathrm{Ki}-67$ ( $\times 40$; depicted by arrowheads). Inset; enlarged image of the doublepositive cell. E, TRA-1-60-positive cells were negative for Ki-67 (arrowheads) 
(A)

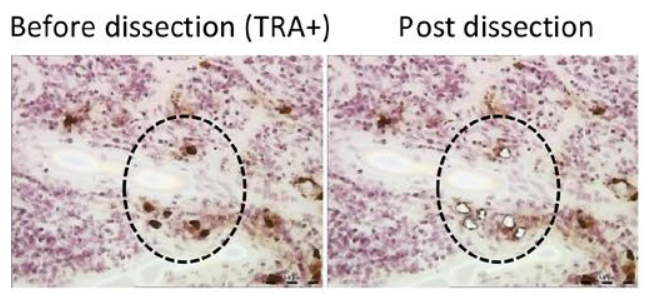

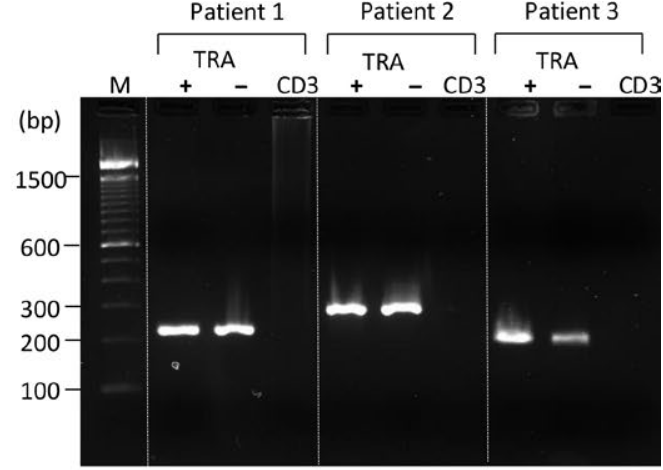

(B)

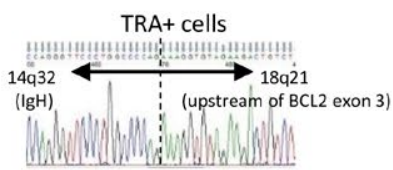

TRA+ cells

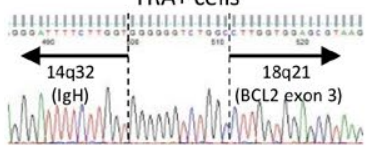

Case 2

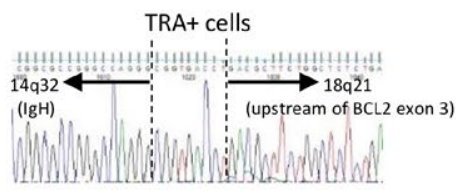

Primary

(C)
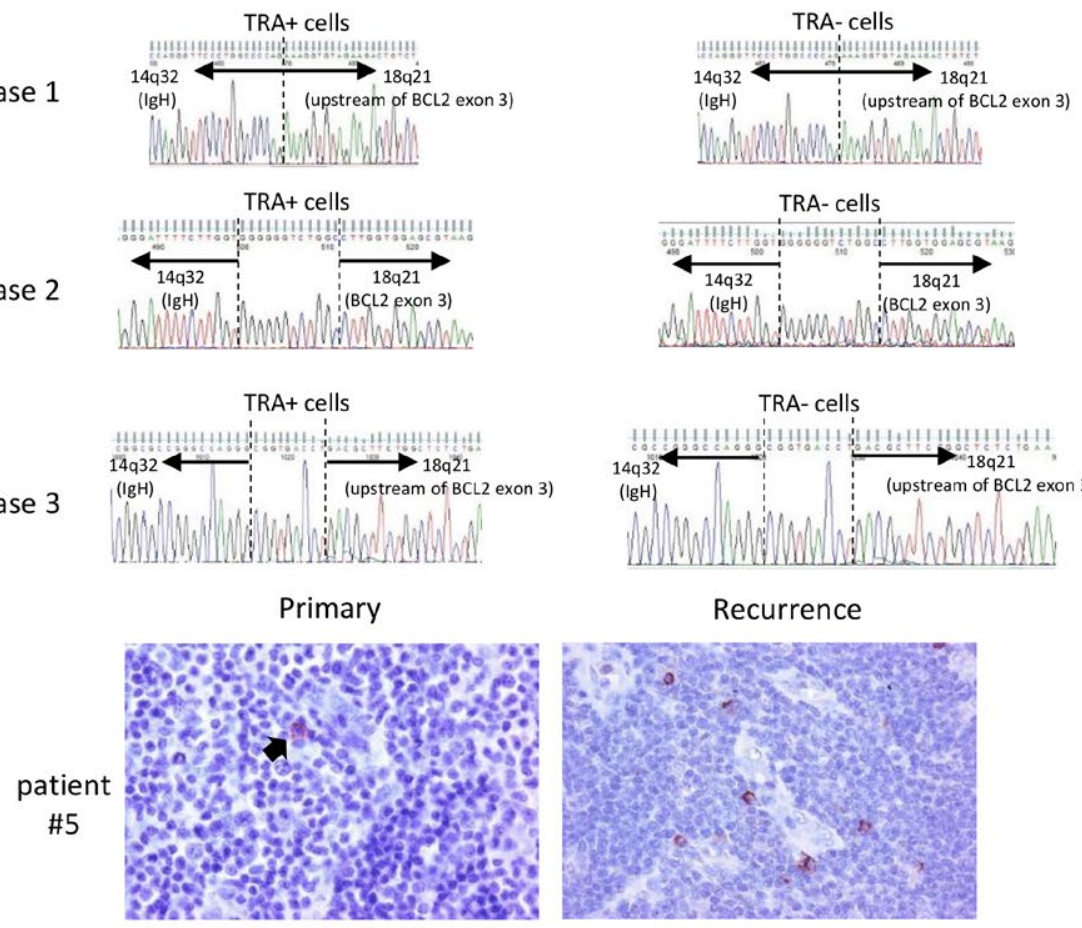

TRA- cells

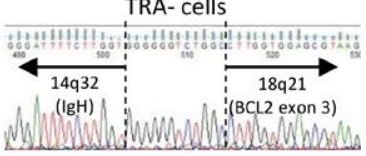

TRA-cells

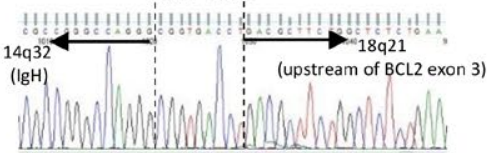

Recurrence

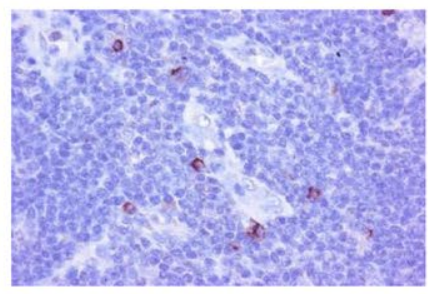

(D)

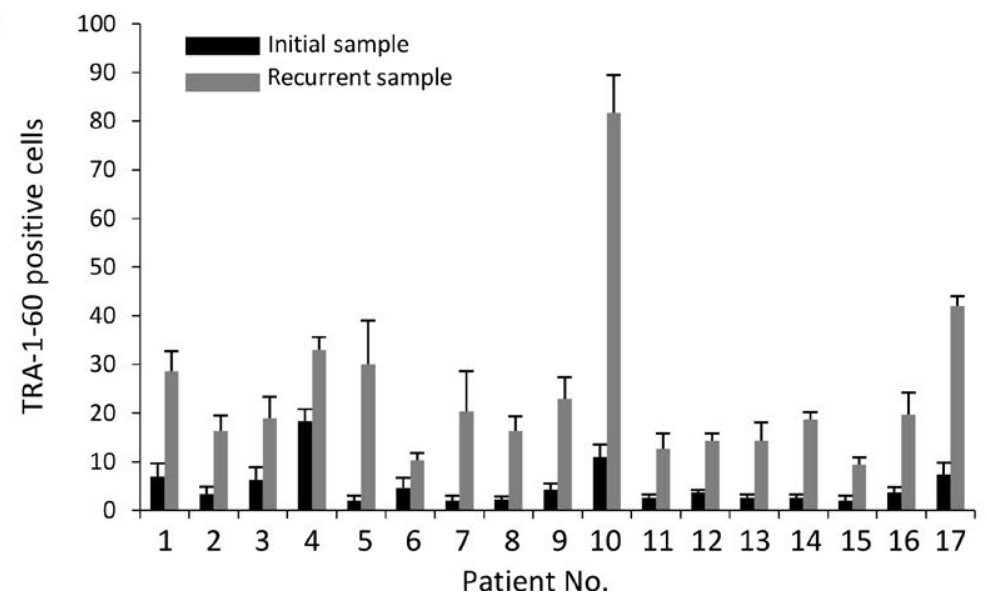

FIG URE 3 Microdissection and long-distance PCR for chromosomal translocation t(14;18), and TRA-1-60 expression in paired primary and relapsed follicular lymphoma (FL) samples. A, Single-cell dissection for TRA-1-60-positive cells on the FL specimen (left panel), and the semi-nested PCR products after long-distance PCR detecting $t(14 ; 18)$ in each FL patient sample. The PCR product from TRA-positive, TRA-negative, and CD3-positive cells were electrophoresed in the same agarose gel. B, Direct DNA sequencing of the amplicons obtained by semi-nested PCR shown in (A). Gel image of each lane by PCR with the same patient number was obtained from the single agarose gel, respectively. C, Compared to the primary sample, the number of TRA-1-60-positive cells in the recurrent samples increased at the perivascular areas of FL tissue. Tissues of patient \#5 are shown. D, TRA-1-60-positive cells increased in all recurrent samples approximately 2 -fold to 8 -fold, and the increase was statistically significant in all pairwise samples (all cases within $P<0.05$ ) 
(A)

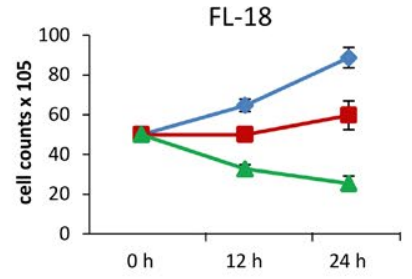

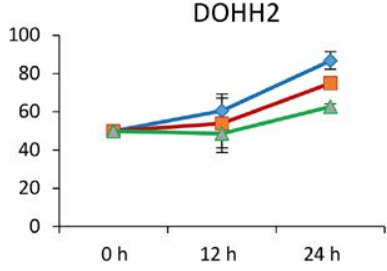

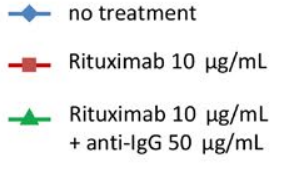

$\sim$ no treatment + anti-lgG $50 \mu \mathrm{g} / \mathrm{mL}$
(B)

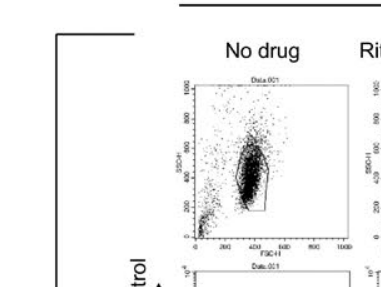

$12 \mathrm{~h}$

Rituximab $10 \mu \mathrm{g} / \mathrm{mL}$ Rituximab $10 \mu \mathrm{g} / \mathrm{mL}$
$+\operatorname{lgG} 50 \mu \mathrm{g} / \mathrm{mL}$

FL-18
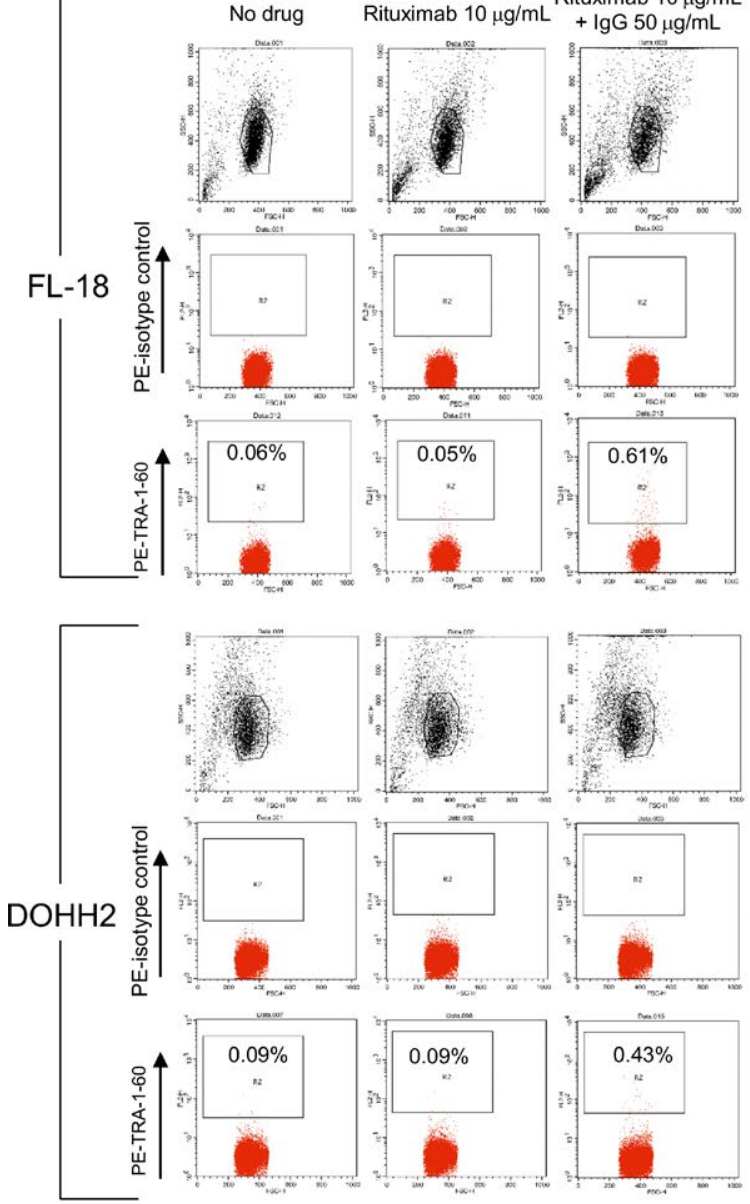

(C)

FL-18

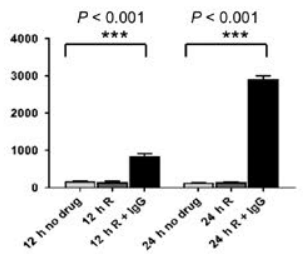

DOHH2

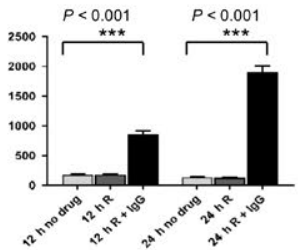

$24 \mathrm{~h}$
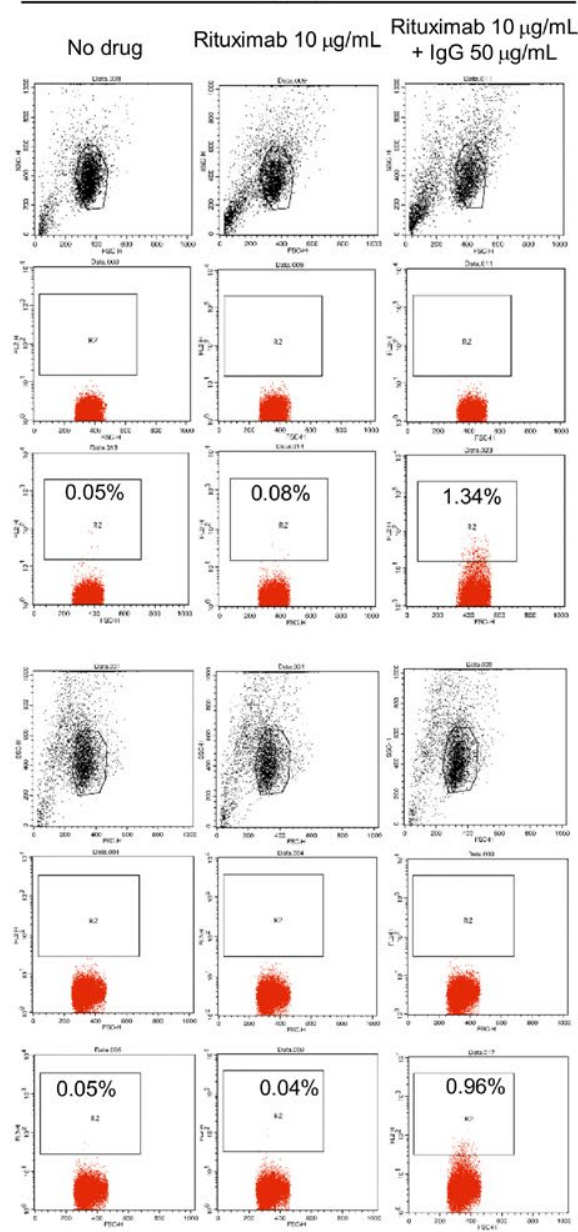

(D)

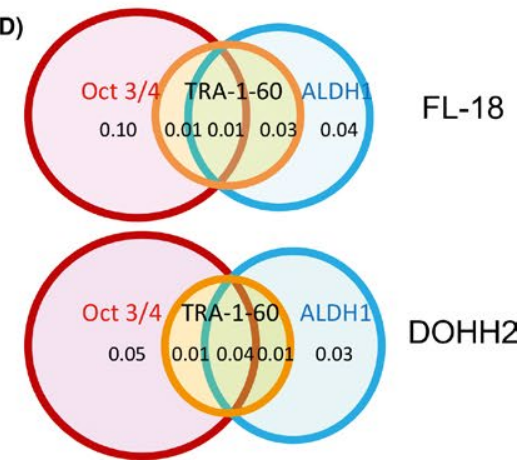

FIG URE 4 Drug treatment assay for the two follicular lymphoma (FL)-derived cell lines, FL-18 and DOHH2, and their difference for TRA-1-60-positive cells with or without rituximab treatment. A, Drug concentration was set to that at which half of the treated cells died. B, In the rituximab-plus-IgG treated group, TRA-1-60-positive cells increased 10 -fold in $12 \mathrm{~h}(0.61 \%$ vs $0.06 \%)$ and 26 -fold (1.34\% vs $0.05 \%)$ in $24 \mathrm{~h}$ in $\mathrm{FL}-18$ cells; and increased 4 -fold $(0.43 \%$ vs $0.09 \%)$ in $12 \mathrm{~h}$ and 19 -fold $(0.96 \%$ vs $0.05 \%)$ in DOHH 2 cells $24 \mathrm{~h}$ after treatment.

$\mathrm{C}$, Results are summarized in the graphs (vertical axis of the graphs in C indicate the number of TRA-positive cells) ${ }^{* * *} P<0.001$, respectively, at all time points). D, Double immunostaining in combination among ALDH1A1, Oct3/4, and TRA-1-60 by FACS analysis shows that TRA-1-60 was detected in a narrower population compared to ALDH1A1 or Oct3/4 
using Annexin V on FL-18 cells showed that the majority of the TRA-1-60-positive cells in the rituximab-treated group was Annexin $\mathrm{V}$-negative, demonstrating drug resistance (Figure S3B). These TRAexpressing lymphoma cells are positive for conventional stem cell markers such as ALDH1A1 and Oct3/4 by FACS analysis (Figure S4). Consequently, the TRA-1-60-positive cell population converges nearly perfectly with the Oct3/4-positive or ALDH1-positive population in both FL-18 and DOHH2 cells (Figure 4D).

\section{6 | Tumor initiation by TRA-1-60-positive FL-18 cells}

TRA-1-60-positive FL-18 cells were purified by FACS Aria. Cell sorting was independently carried out three times, and each time the purity of the positive cell fraction was approximately $70 \%$, whereas the negative fraction contained $0.1 \%$ of TRA-positive cells among total cells (Figure 5A). From each sorted sample, $2 \times 10^{3}$ of the TRApositive and TRA-negative cells were s.c. implanted on opposite sides of the back of the same NOD/SCID mouse, respectively. Three months after transplantation, tumor development was evaluated in each mouse. Subsequently, evident tumor formation was observed in the TRA-1-60-positive population, whereas the TRA-1-60negative population developed diminutive, or no tumors (Figure $5 B$, left images, Figure S5). Both the average volume and weight of the tumors from mice implanted with purified TRA-positive cells were approximately 10 -fold greater than those from the TRA-negative fraction (Figure 5B, right graphs). Histology of the resultant tumors showed nodular proliferation of human CD20-positive large B-cell lymphoma (Figure 5C). TRA-1-60-expressing tumor cells were immunohistochemically detected at a similar frequency to those from FL patient samples.

\section{7 | TRA-1-60-expressing cells showed resistance to therapeutic agents}

In vivo tumor-initiating capacity of TRA-expressing cells inspired our detailed assessment of the cellular response to the present clinical agents against B-cell lymphomas. Using the two FL lines, FL-18 and $\mathrm{DOHH}$, as a model, drug response of the TRA-1-60-positive cellular fraction was compared with that of the TRA-1-60-negative fraction (total of $5 \times 10^{4}$ cells prepared by sorting, respectively). Each fraction was treated with bendamustine alone, or with rituximab in combination with bendamustine, and subsequently examined for apoptotic induction using Annexin $\mathrm{V}$ at 24 hours after drug treatment. In the bendamustine-treated group of FL-18 and $\mathrm{DOHH} 2$, apoptotic cell numbers were significantly lower in the TRA-1-60positive cell fraction than in the TRA-1-60-negative fraction in each line $(P<0.0001$ and $P=0.0014<0.005$, respectively). A similar phenomenon was observed in the combination treatment of rituximab with bendamustine in each line $(P<0.0001$ and $P<0.001$, respectively) (Figure 6A,B), indicating that the TRA-1-60-positive cell population was markedly resistant to current therapeutic agents for B-cell lymphomas.

\section{8 | Molecular signature of TRA-1-60-expressing follicular lymphoma cells}

TRA-1-60-positive FL cells from FL-18 and DOHH2 were enriched by FACS Aria by more than $70 \%$ and the enriched population showed a majority of the cells in G0/G1 cycle arrest (Figures S6A,B and S7A,B).

To genetically overview the phenotypic characteristics of the TRA-1-60-expressing population, gene expression profile was carried out with both TRA-1-60-positive and TRA-1-60-negative populations of $\mathrm{FL}-18$ and $\mathrm{DOHH}-2$ cell lines. Detailed information with gene names and fold changes are shown in Tables S1-S4, and supervised hierarchical clustering on 406 differentially expressed gene is shown in Figure S8. As transporter genes including solute carrier (SLC) family genes were listed in the top 20 genes in the upregulated gene categories according to the $P$-value and $Q$-value, we more thoroughly investigated the refractory molecules by focusing on drug transporter and cancer chemoresistance genes using real-time RT-PCR between TRApositive cells and TRA-negative cells from FL-18 and DOHH2, respectively. ${ }^{22-24}$ Results of expression profiling showed a similar molecular signature between FL-18 and DOHH2 (Figure 6C, Tables S5 and S6). In detail, expression of $A B C$ transporters including $A B C A 13, A B C B 11$, $A B C B 5$, SLCO1B3 on TRA-1-60-positive cells was increased more than three-fold (Table S5) compared with those on TRA-negative cells both in $\mathrm{FL}-18$ and $\mathrm{DOHH} 2$, and expression of $\mathrm{ABCG} 8$ was upregulated to 14 -fold in the TRA-positive FL-18 population (Table S5). Among the CYP (cytochrome P450) genes, expression of CYP2C9 on TRA-1-60positive cells was increased to over three-fold; subsequently, those of CYP1A1, 1A2, 2B6, 2C19, 3A4, and $3 A 5$ were augmented by comparison with those of the negative fraction in the same line (Table S6). Moreover, some of the tumor-related transcription factors and receptors such as Fos, TNFRSF11a (over three-fold), followed by MET, CDKN2D, EGFR, ERBB4, ESR2, MVP, SULTE1 and NFkBIE etc. were induced by their expression in the TRA-1-60-positive population compared with those in the negative population (Table S6). Among these, upregulation of immediate early gene, $c$-fos, expression was remarkably high in the TRA-1-60-positive population (74-fold upregulation in $\mathrm{DOHH} 2$, 13-fold upregulation in FL). Consequently, as a noticeable tendency, expression of multiple genes categorized to drug transporters and the CYP family were significantly induced in TRA-160-positive lymphoma cells in contrast to TRA-negative cells, which supported the drug-resistant characteristics of the TRA-positive population as was shown in the heatmap analysis and in the tables.

\section{4 | DISCUSSION}

For most B-cell lymphomas, it is widely accepted that rituximab has contributed to disease-free survival. ${ }^{25}$ However, a serious clinical concern, especially for intractable lymphomas, is frequent tumor relapse under rituximab treatment and one of these is represented by follicular lymphomas. Recently, the concept of the "cancer initiating cell" has gained traction for explaining therapeutic failure and relapse for several types of malignancies, because of their 
(A)
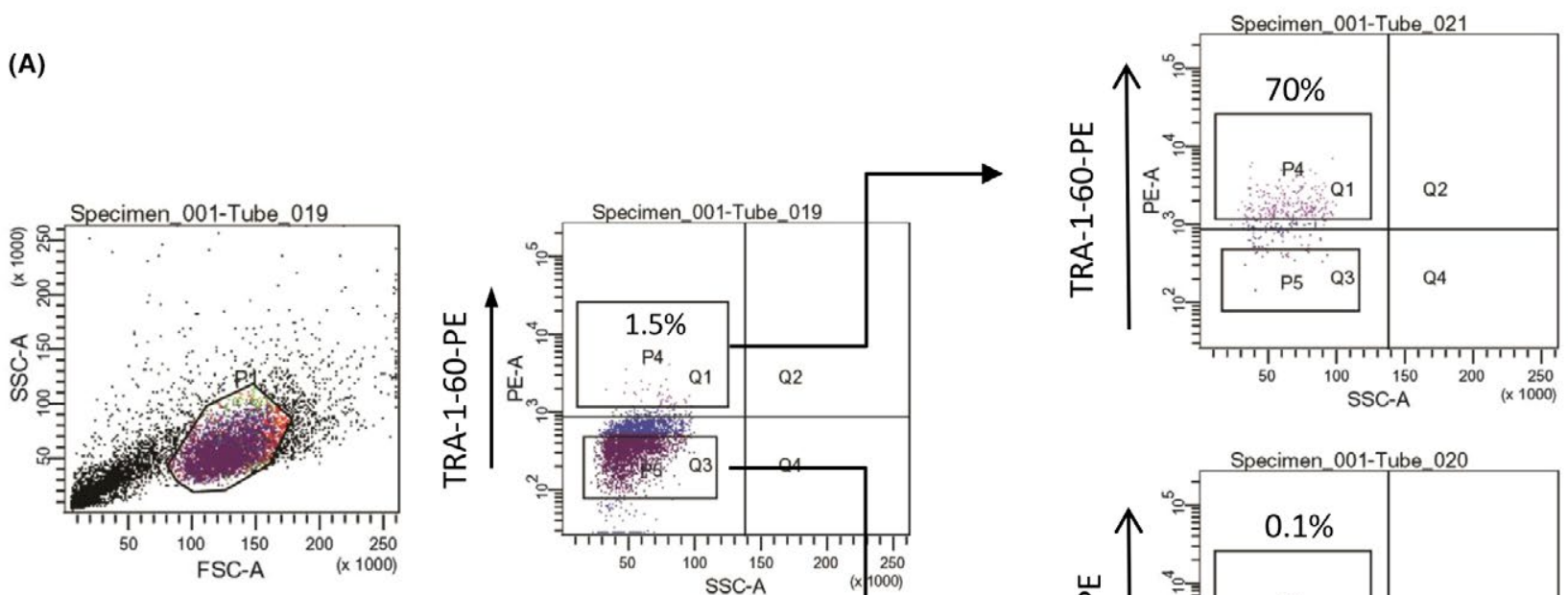

(B)
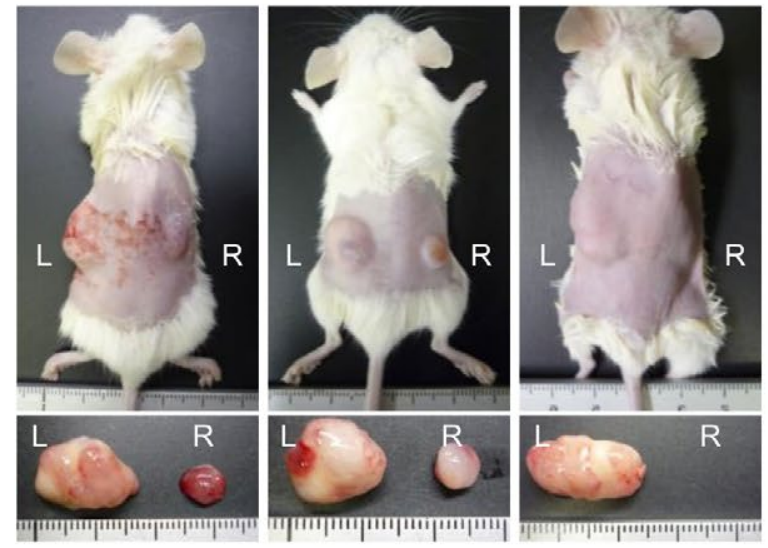

TRA-1-60 +

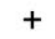

$-$

$+$
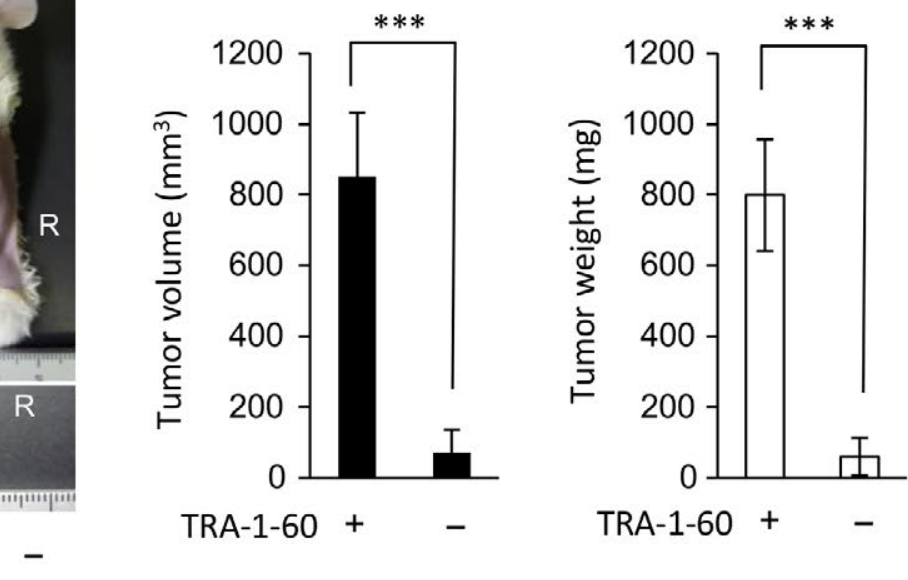

no tumor

TRA-1-60 +
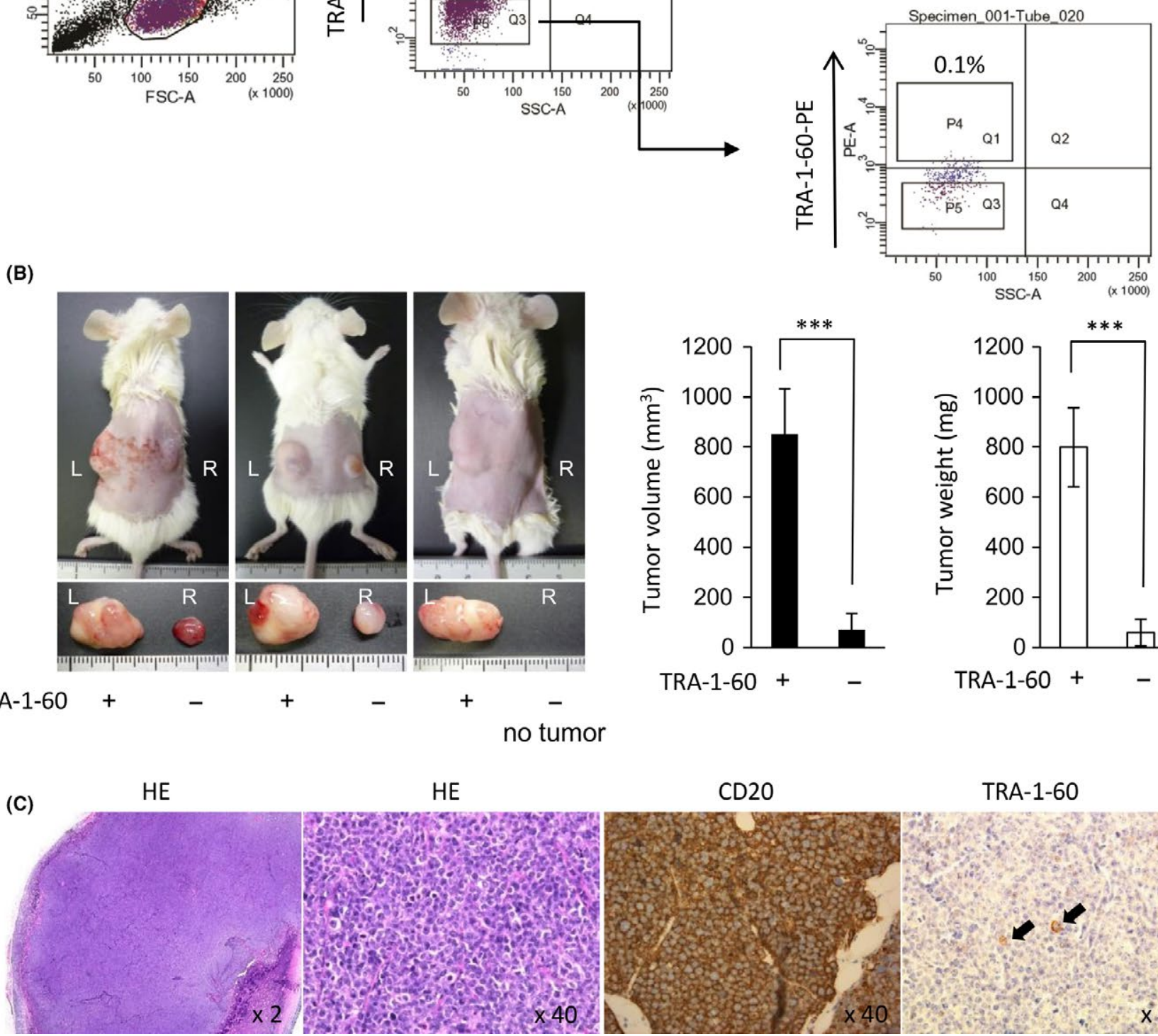

CD20

TRA-1-60
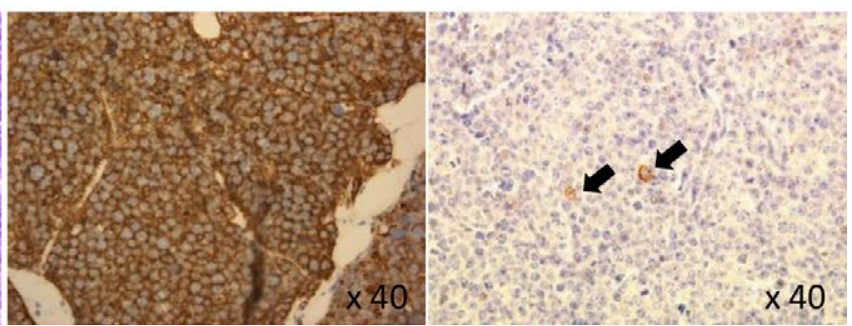

FIG URE 5 Results of sorting for TRA-1-60-positive cells and tumor-forming capacity for the in vivo model. A, Purity of sorted TRA-160-positive population was approximately 70\%. B, Results of implantation to NOD/SCID mouse. All but one TRA-1-60-negative population formed tumors (left). Tumor volume and tumor weight (right, ${ }^{* * *} P<0.001$ ). C, Histology of xenograft tumors shows vague nodular proliferation of human CD20-positive large B-cell lymphoma

therapeutically resistant feature against antitumor agents and irradiation. ${ }^{21}$ In the meantime, studies in the field of regenerative medicine have provided information about several critical cellular markers such as Oct3/4 and ALDH1 for identifying the stem cell, and TRA-1-60 has been reported as the most reliable indicator among these. ${ }^{14}$

In the present study, our aim was to find a clue for such recalcitrance of follicular lymphomas, which may clinically lead to recurrence and fatal 
(A)

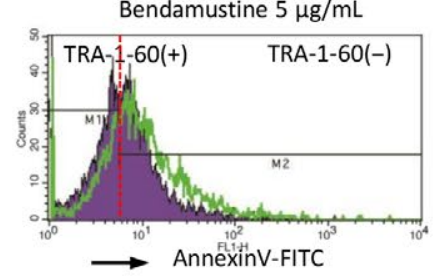

FL-18

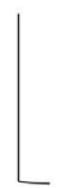

Rituximab $10 \mu \mathrm{g} / \mathrm{mL}+\lg G 50 \mu \mathrm{g} / \mathrm{mL}$ + Bendamustine $5 \mu \mathrm{g} / \mathrm{mL}$

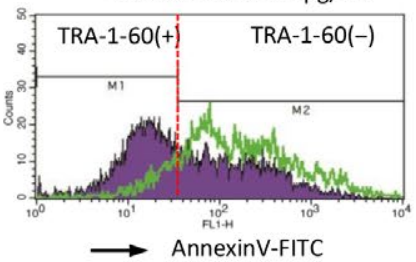

(B)
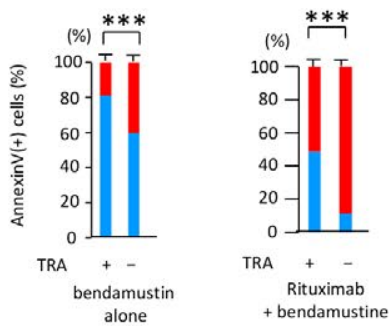

DOHH2

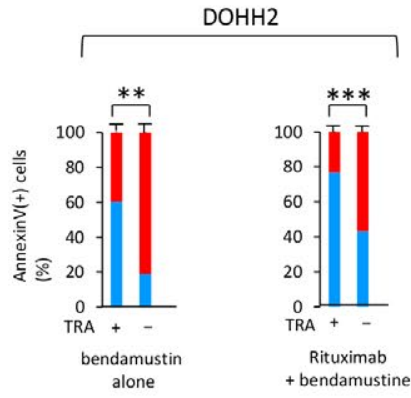

Bendamustine $1 \mu \mathrm{g} / \mathrm{mL}$

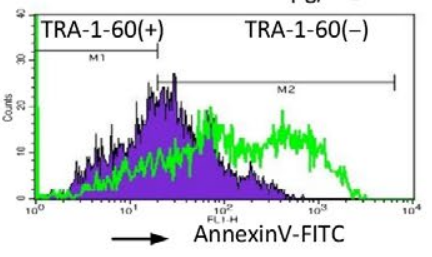

Rituximab $10 \mu \mathrm{g} / \mathrm{mL}+\operatorname{lgG} 50 \mu \mathrm{g} / \mathrm{mL}$ + Bendamustine $1 \mu \mathrm{g} / \mathrm{mL}$

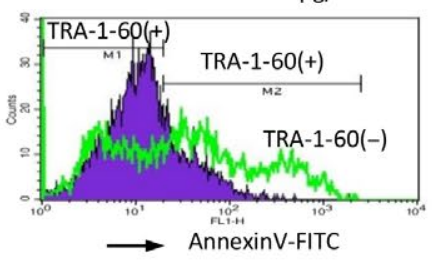

(C)

Drug resistance gene clustered

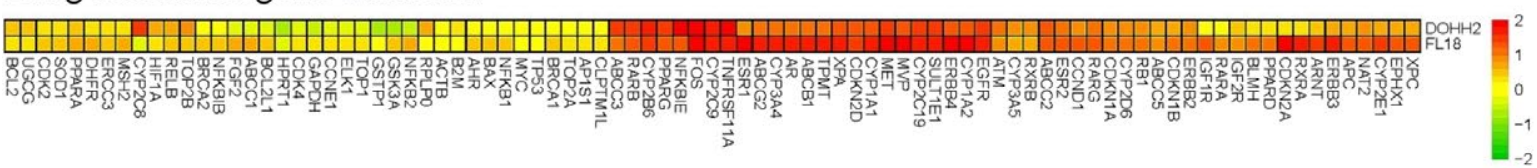

(TRA+/TRA- = fold)

\section{Drug Transporters clustered}

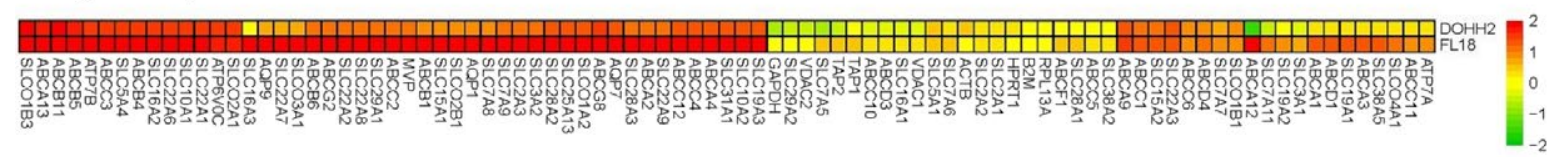

(TRA+/TRA- = fold)

FIG URE 6 Drug sensitivity assay for TRA-1-60-positive or -negative population and molecular signature of the TRA-1-60-positive lymphoma cells. A, In the bendamustine treatment group, there were fewer apoptotic cells in the TRA-1-60-positive population than in the TRA-1-60-negative population both in FL-18 and DOHH2; there were fewer apoptotic cells within the TRA-1-60-positive population in the rituximab-plus-bendamustine treatment group in these two follicular lymphoma (FL) lines. B, Apoptotic induction on TRA-positive and -negative fractions of the two FL lines in response to bendamustine alone (left graph), or rituximab-plus-bendamustine (right graph). Data were obtained from the FACS analysis shown in (A) $\left.{ }^{* *} P<0.01,{ }^{* * *} P<0.001\right)$. C, Heatmap visualization of the expression profiling covering 168 drug resistance-related genes. Fold change of a target gene expression in the FL-18 and DOHH2 cell lines was calculated by dividing the expression value of TRA(+) by that of TRA(-), and it was log2 transformed 
progression. From this point of view, it might be reasonable that TRA-1-60expressing lymphoma cells consequently share biological characteristics with conventional cancer stem cells to some extent, although the details remain unclear as to whether or not they actually have self-renewal ability and are actual progenitors of FL. We first screened germinal centers of reactive lymphoid tissue and found that TRA-1-60-expressing B lymphocytes were recognized as a scattered pattern inside germinal centers without mitotic activity, unlike most of the germinal center cells showing Ki-67 positivity. As a neoplastic counterpart, they were also detected in follicular lymphoma tissues with similar frequency, which was demonstrated by $\mathrm{t}(14 ; 18)(\mathrm{q} 32$; q21) chromosomal translocation (bcl-2/lgH fusion). These cells were predominantly located at perivascular areas in the FL tissues. Significantly, the number of TRA-1-60-positive cells was markedly elevated in the recurrent samples from patients with FL who received R-CHOP therapy relative to the primary samples from the same patient. Supporting the results of tissue analysis, an in vitro assay using FL-18 and DOHH2 as a FL model line demonstrated the escape of TRA-1-60-expressing cells from elimination by rituximab. Thus, the resistance of these cells was corroborated by antitumor drug assay. Moreover, they immunophenotypically converged to the Oct3/4 and ALDH1-positive population, indicating TRA-1-60 is a potent marker for stress resistance which might be related to stemness. Indeed, xenografting only small numbers of TRA-1-60-expressing cells (approximately 1400 of TRA+ cells) led to tumor formation in NOD/SCID mice, whereas the negative fraction developed no prominent tumors.

Recently, besides the current standard chemotherapy of R-CHOP, treatment by bendamustine combined with rituximab has emerged as a more effective therapy for relapsed or refractory FL. This advanced therapy is reported to improve progression-free survival, ${ }^{26}$ and is expected to be the first-line treatment approach going forward. However, TRA-1-60-positive populations showed pronounced resistance to bendamustine as well as to rituximab, which may be partly explained by simultaneous upregulation of diverse isotypes of $A B C$ transporter and CYP genes as was demonstrated by expression profiling, held to impart resistance to antitumor agents. Moreover, several genes such as Fos, MET, NFkBIE, and TNFRSF11a (also known as RANK) were found to be upregulated in TRA-1-60-expressing FL cells, which have been reported to play diverse roles in tumorigenesis, intractability against therapeutics, and induction of stem-like phenotype to tumors. ${ }^{27,28}$ Especially, upregulation of c-Fos, an immediate early transcription factor gene, was the most remarkable; however, its concrete function in TRA-1-60-expressing FL cells remains unclear in this study.

We conclude that, although further investigation for molecular insights will be necessary, it is now clear that TRA-1-60 should be a prominent focus among cellular markers in follicular lymphoma research, by which we ultimately hope to explain clinical intractability against current rituximab-combination and other therapies, and to better understand the unique population among a range of lymphoma cell types.

\section{ACKNOWLEDGMENTS}

The authors are grateful to Dr Kyl Myrick for critical reading of the manuscript. We also thank Ms Mutsumi Okabe and Mr Yukinari
Isomoto (Okayama Univ.) and Central Research Laboratory for technical assistance, and BC Cancer Research Centre for cell sorting by FACS Aria. This research was supported by Grant-in-Aid for Scientific Research No. 24790350 (K.T.) and No. 16K15245 (E.K.) from the Japan Society for the Promotion of Science (JSPS).

\section{CONFLICTS OF INTEREST}

Authors declare no conflicts of interest for this article.

\section{ORCID}

Katsuyoshi Takata (iD http://orcid.org/0000-0001-6890-1276

\section{REFERENCES}

1. Swerdlow SHCE, Harris NL, Jaffe ES, et al., eds. WHO Classification of Tumours of Haematopoietic and Lymphoid Tissues. Lyon: IARC; 2008.

2. Press OW, Unger JM, Rimsza LM, et al. Phase III randomized intergroup trial of CHOP plus rituximab compared with $\mathrm{CHOP}$ chemotherapy plus (131)iodine-tositumomab for previously untreated follicular non-Hodgkin lymphoma: SWOG S0016. J Clin Oncol. 2013;31:314-320.

3. Green MR, Gentles AJ, Nair RV, et al. Hierarchy in somatic mutations arising during genomic evolution and progression of follicular lymphoma. Blood. 2013;121:1604-1611.

4. Green MR, Kihira S, Liu CL, et al. Mutations in early follicular lymphoma progenitors are associated with suppressed antigen presentation. Proc Natl Acad Sci USA. 2015;112:E1116-E1125.

5. Okosun J, Bodor C, Wang J, et al. Integrated genomic analysis identifies recurrent mutations and evolution patterns driving the initiation and progression of follicular lymphoma. Nat Genet. 2014;46:176-181.

6. Pasqualucci L, Khiabanian H, Fangazio M, et al. Genetics of follicular lymphoma transformation. Cell Rep. 2014;6:130-140.

7. Ishikawa F, Yoshida S, Saito Y, et al. Chemotherapy-resistant human AML stem cells home to and engraft within the bone-marrow endosteal region. Nat Biotechnol. 2007;25:1315-1321.

8. Raj D, Aicher A, Heeschen C. Concise review: stem cells in pancreatic cancer: from concept to translation. Stem Cells. 2015;33:2893-2902.

9. Bleau AM, Hambardzumyan D, Ozawa T, et al. PTEN/PI3K/Akt pathway regulates the side population phenotype and ABCG2 activity in glioma tumor stem-like cells. Cell Stem Cell. 2009;4:226-235.

10. Ikeda J, Mamat S, Tian T, et al. Tumorigenic potential of mononucleated small cells of Hodgkin lymphoma cell lines. Am J Pathol. 2010;177:3081-3088.

11. Kikushige $\mathrm{Y}$, Ishikawa F, Miyamoto $\mathrm{T}$, et al. Self-renewing hematopoietic stem cell is the primary target in pathogenesis of human chronic lymphocytic leukemia. Cancer Cell. 2011;20:246-259.

12. Takahashi K, Yamanaka S. Induction of pluripotent stem cells from mouse embryonic and adult fibroblast cultures by defined factors. Cell. 2006;126:663-676.

13. Yamanaka S. Strategies and new developments in the generation of patient-specific pluripotent stem cells. Cell Stem Cell. 2007;1:39-49.

14. Chan EM, Ratanasirintrawoot $\mathrm{S}$, Park IH, et al. Live cell imaging distinguishes bona fide human iPS cells from partially reprogrammed cells. Nat Biotechnol. 2009;27:1033-1037.

15. Tanabe K, Nakamura M, Narita M, Takahashi K, Yamanaka S. Maturation, not initiation, is the major roadblock during reprogramming toward pluripotency from human fibroblasts. Proc Natl Acad Sci USA. 2013;110:12172-12179. 
16. Schopperle WM, DeWolf WC. The TRA-1-60 and TRA-1-81 human pluripotent stem cell markers are expressed on podocalyxin in embryonal carcinoma. Stem Cells. 2007;25:723-730.

17. Ardighieri L, Zeppernick F, Hannibal CG, et al. Mutational analysis of BRAF and KRAS in ovarian serous borderline (atypical proliferative) tumours and associated peritoneal implants. J Pathol. 2014;232:16-22.

18. Albinger-Hegyi A, Hochreutener B, Abdou MT, et al. High frequency of $t(14 ; 18)$-translocation breakpoints outside of major breakpoint and minor cluster regions in follicular lymphomas: improved polymerase chain reaction protocols for their detection. Am J Pathol. 2002;160:823-832.

19. Stolz C, Hess G, Hahnel PS, et al. Targeting Bcl-2 family proteins modulates the sensitivity of B-cell lymphoma to rituximab-induced apoptosis. Blood. 2008;112:3312-3321.

20. Mizukami Y, Jo WS, Duerr EM, et al. Induction of interleukin-8 preserves the angiogenic response in HIF-1alpha-deficient colon cancer cells. Nat Med. 2005;11:992-997.

21. Dean M, Fojo T, Bates S. Tumour stem cells and drug resistance. Nat Rev Cancer. 2005;5:275-284.

22. Ohno H, Doi S, Fukuhara S, Nishikori M, Uchino H, Fujii H. A newly established human lymphoma cell line, FL-18, carrying a $14 ; 18$ translocation. Japanese journal of cancer research. Gann. 1985;76:563-566.

23. Amakawa R, Fukuhara $\mathrm{S}$, Ohno $\mathrm{H}$, et al. Genomic organization of $\mathrm{IgH}$ gene compared with the expression of $\mathrm{Bcl}-2$ gene in $\mathrm{t}(14 ; 18)-$ positive lymphoma. Blood. 1991;77:1970-1976.

24. Kluin-Nelemans HC, Limpens J, Meerabux J, et al. A new nonHodgkin's B-cell line (DoHH2) with a chromosomal translocation $\mathrm{t}(14 ; 18)(\mathrm{q} 32 ; \mathrm{q} 21)$. Leukemia. 1991;5:221-224.
25. Rummel MJ, Niederle N, Maschmeyer G, et al. Bendamustine plus rituximab versus $\mathrm{CHOP}$ plus rituximab as first-line treatment for patients with indolent and mantle-cell lymphomas: an open-label, multicentre, randomised, phase 3 non-inferiority trial. Lancet. 2013;381:1203-1210.

26. Fiumara P, Snell V, Li Y, et al. Functional expression of receptor activator of nuclear factor kappaB in Hodgkin disease cell lines. Blood. 2001;98:2784-2790.

27. Compagno M, Lim WK, Grunn A, et al. Mutations of multiple genes cause deregulation of NF-kappaB in diffuse large B-cell lymphoma. Nature. 2009;459:717-721.

28. van Leenders GJ, Sookhlall R, Teubel WJ, et al. Activation of c-MET induces a stem-like phenotype in human prostate cancer. PLoS One. 2011;6:e26753.

\section{SUPPORTING INFORMATION}

Additional supporting information may be found online in the Supporting Information section at the end of the article.

How to cite this article: Takata K, Saito K, Maruyama S, et al. Identification of TRA-1-60-positive cells as a potent refractory population in follicular lymphomas. Cancer Sci. 2019;110:443-457. https://doi.org/10.1111/cas.13870 